\title{
Preparation and Properties of a Novel Microcrystalline Cellulose-Filled Composites Based on Polyamide 6/High-Density Polyethylene
}

\author{
Shihua Xu ${ }^{1}$, Shunmin $\mathrm{Yi}^{1}$, Jun He ${ }^{2}$, Haigang Wang ${ }^{1}$, Yiqun Fang ${ }^{1, *}$ and Qingwen Wang ${ }^{1,3, *}$ \\ 1 Key Laboratory of Bio-based Material Science and Technology (Ministry of Education), \\ Northeast Forestry University, Harbin 150040, China; xush@nefu.edu.cn (S.X.); \\ binshanmu@nefu.edu.cn (S.Y.); hgwang@nefu.edu.cn (H.W.) \\ 2 Nanjing Xuhua Sundi New Building Materials Co., Ltd., Nanjing 211224, China; xush@nefu.edu.cn \\ 3 College of Materials and Energy, South China Agricultural University, Guangzhou 510642, China \\ * Correspondence: yqfang@nefu.edu.cn (Y.F.); qwwang@scau.edu.cn (Q.W.); \\ Tel.: +86-451-8219-0932 (Y.F. \& Q.W.)
}

Academic Editor: Armando Silvestre

Received: 13 May 2017; Accepted: 10 July 2017; Published: 16 July 2017

\begin{abstract}
In the present study, lithium chloride $(\mathrm{LiCl})$ was utilized as a modifier to reduce the melting point of polyamide 6 (PA6), and then $15 \mathrm{wt} \%$ microcrystalline cellulose (MCC) was compounded with low melting point PA6/high-density polyethylene (HDPE) by hot pressing. Crystallization analysis revealed that as little as $3 \mathrm{wt} \% \mathrm{LiCl}$ transformed the crystallographic forms of PA6 from semi-crystalline to an amorphous state (melting point: $220^{\circ} \mathrm{C}$ to none), which sharply reduced the processing temperature of the composites. $\mathrm{LiCl}$ improved the mechanical properties of the composites, as evidenced by the fact that the impact strength of the composites was increased by $90 \%$. HDPE increased the impact strength of PA6/MCC composites. In addition, morphological analysis revealed that incorporation of $\mathrm{LiCl}$ and maleic anhydride grafted high-density polyethylene (MAPE) improved the interfacial adhesion. $\mathrm{LiCl}$ increased the glass transition temperature of the composites (the maximum is $72.6^{\circ} \mathrm{C}$ ).
\end{abstract}

Keywords: lithium chloride; microcrystalline cellulose; polyamide 6/high-density polyethylene; melting point

\section{Introduction}

Over the last two decades, studies about polymer blends based on polyamide 6 (PA6) and high-density polyethylene (HDPE) have received a great deal of interests. As an engineering plastic, PA6 is widely used in engineering domains for its excellent rigidity, thermal stability, and high mechanical performance. However, high cost and brittleness have limited its application. On the other hand, as one of the most promising common plastics, HDPE has many advantages, including low cost, high impact strength, good processability, and significant damping. However, HDPE has some inherent weaknesses, such as low heat deflection temperature and weak rigidity. Thereby, blends of PA6 and HDPE may result in polymers with a synergic combination of these properties to overcome their disadvantages [1-8].

Although polymers based on petroleum are in widespread use all over the world, what follow are sharp environmental issues. Bio-based materials are regarded as having some of the greatest potential to replace and reduce the depletion of fossil resources [9,10], which is due to the unique properties of natural fibers, including biodegradability, renewability, high mechanical properties, low cost, and density [11]. In contrast with other natural fibers, microcrystalline cellulose (MCC) with high specific 
surface area and crystallinity has received much attention, where the amorphous regions have been removed by hydrolysis process [11,12].

The thermodynamical immiscibility of PA6 and HDPE leads to poor interfacial adhesion. Thereby, a large number of studies focused on interface issues by using various compatibilizers, such as maleic anhydride grafted with high-density polyethylene (MAPE), styrene-b-ethylene-co-butylene-b-styrene grafted with maleic anhydride (SEBS-g-MA), and ethylene-b-glycidyl methacrylate (E-GMA), etc. [13-15]. However, it is very difficult to prepare natural fibers reinforced with PA6/HDPE blends, due to the conflicts of the high melting point of PA6 and the low degradation temperature of natural fibers. Some efforts were considered to figure out this problem. Reducing the melting point of polyamides is an effective method, and an increase in the number of papers indicates that small amounts of lithium chloride $(\mathrm{LiCl})$ could decrease the melting point of PA6; then PA6 and wheat straws were blended together to prepare PA6/wheat straw composites. The results indicated that $\mathrm{LiCl}$ increased the tensile and flexural modulus, but decreased the impact strength, the tensile strength, and the flexural strength [16-18].

In this paper, $\mathrm{LiCl}$ was used to decrease the melting point of $\mathrm{PA} 6$ and the processing temperature, and improve the mechanical properties of the composites. HDPE was used to improve the impact strength of the composites. The effects of various $\mathrm{LiCl}$ and MAPE contents on crystal, mechanical, morphological, and thermal properties of the resulting composites were studied.

\section{Materials and Methods}

\subsection{Materials}

Commercially-available PA6 (1013b) with a density of $1.14 \mathrm{~g} / \mathrm{cm}^{3}$ and a melt flow index of $22 \mathrm{~g} / 10 \mathrm{~min}\left(235^{\circ} \mathrm{C}, 2.16 \mathrm{~kg}\right)$, was purchased from UBE Industries (Tokyo, Japan). LiCl (analytical reagent), supplied by Rgent Industries Ltd (Tianjin, China)., was applied to decrease the melting point of PA6. HDPE (5000S) was purchased from Daqing Petrochemical (Daqing, China) with a density of $0.954 \mathrm{~g} / \mathrm{cm}^{3}$ and a melt flow index of $0.7 \mathrm{~g} / 10 \mathrm{~min}\left(190^{\circ} \mathrm{C}, 2.16 \mathrm{~kg}\right.$ according to ASTM D1238). MAPE (A-C ${ }^{\circledR} 575 \mathrm{~A}$ ) was supplied by Honeywell International (Shanghai, China) with a maleic anhydride grafting ratio of $3 \mathrm{wt} \%$. MCC (food grade) was purchased from Hongyuan Food Additives (Guangzhou, China) with the effective substance of $99 \%$. The MCC was a powder with a particle size range from $26 \mu \mathrm{m}$ to $96 \mu \mathrm{m}$ and the average particle was $50 \mu \mathrm{m}$.

\subsection{Sample Preparation}

Prior to compounding, PA6, MCC, and $\mathrm{LiCl}$ were dried at $103^{\circ} \mathrm{C}$ for $12 \mathrm{~h}$ in an oven, and $\mathrm{LiCl}$ was ground into particles that passed through a 100-mesh screen; then PA6, HDPE, MAPE, and LiCl were blended in a Haake torque rheometer (Thermo Fisher Scientific, Waltham, MA, USA) at $230{ }^{\circ} \mathrm{C}$ for $5 \mathrm{~min}$ with the speed of $50 \mathrm{rpm}$ (The blends of PA6, HDPE, MAPE, and $\mathrm{LiCl}$ was abbreviated as the plastics blends in the context). The variation of two components was considered: (1) the weight ratio of PA6, HDPE, and MAPE was kept at 60/30/10. The LiCl content in the plastics blends was $0 \%, 0.5 \%, 1.0 \%, 1.5 \%, 2.0 \%, 2.5 \%$, and $3.0 \%$; and (2) The $\mathrm{LiCl}$ content in the plastics blends was kept at $1.0 \%$. The weight ratio of PA6, HDPE and MAPE was $60 / 35 / 5,60 / 25 / 15$, and $60 / 20 / 20$. The plastic blends were crushed into granules in the crushing mill, respectively.

The plastics blends and MCC with the weight ratio of 85/15 were mixed in a Haake torque rheometer (Thermo Fisher Scientific, Waltham, MA, USA) at $230{ }^{\circ} \mathrm{C}$ for $5 \mathrm{~min}$ with the speed of $50 \mathrm{rpm}$. Subsequently, the blends were hot-pressed at $10 \mathrm{MPa}$ for $10 \mathrm{~min}$. To investigate the effect of HDPE on the composites, PA6/MCC composites was prepared. PA6 and MCC with the weight ratio of 85/15 were mixed in a Haake torque rheometer at $230{ }^{\circ} \mathrm{C}$ for $5 \mathrm{~min}$ with the speed of $50 \mathrm{rpm}$. Then the blends were hot-pressed at $10 \mathrm{MPa}$ for $10 \mathrm{~min}$. To reduce the energy consumption, the processing temperature was set to $20^{\circ} \mathrm{C}$ above the melting point which tested by differential scanning calorimetry (DSC). For the composites with no melting point, the processing temperature was set to $200^{\circ} \mathrm{C}$ (Table 1). 
Table 1. Formulation and processing temperature of the composites.

\begin{tabular}{cccc}
\hline Samples & LiCl $\mathbf{( w t} \%)$ & MAPE $(\mathbf{w t} \mathbf{\%})$ & Processing Temperature $\left({ }^{\circ} \mathbf{C}\right)$ \\
\hline L0 & 0 & 10 & 240 \\
L0.5 & 0.5 & 10 & 235 \\
L1.0 & 1 & 10 & 230 \\
L1.5 & 1.5 & 10 & 225 \\
L2.0 & 2 & 10 & 220 \\
L2.5 & 2.5 & 10 & 210 \\
L3.0 & 3 & 10 & 200 \\
M5 & 1 & 5 & 230 \\
M15 & 1 & 15 & 230 \\
M20 & 1 & 20 & 230 \\
R & 0 & 0 & 240
\end{tabular}

$\mathrm{LiCl}$ (wt \%): $\mathrm{LiCl}$ content in PA6/HDPE/MAPE/LiCl blends by weight; MAPE (wt \%): MAPE content in PA6/HDPE/MAPE blends by weight (the weight ratio of PA6 was kept at $60 \%$ ). Abbreviations of L0 - L3.0 represent the composites with the $\mathrm{LiCl}$ content of $0 \%, 0.5 \%, 1.0 \%, 1.5 \%, 2.0 \%, 2.5 \%$, and $3.0 \%$. Abbreviations of M5, M15, and M20 represent the composites with the MAPE content of $5 \%, 15 \%$, and $20 \%$. R represents PA6/MCC composites.

\subsection{Characterization}

\subsubsection{Differential Scanning Calorimetry}

The non-isothermal crystallization and melting process of the composites were analyzed using Differential Scanning Calorimetry (DSC) (Pyris6, Perkin Elmer, Waltham, MA, USA) with a sample weight of 4-6 mg. All samples were heated to $230{ }^{\circ} \mathrm{C}$ and held for $10 \mathrm{~min}$ to wipe out the thermal history, and then cooled to $60^{\circ} \mathrm{C}$ with the cooling rate of $10{ }^{\circ} \mathrm{C} / \mathrm{min}$, finally heated to $230{ }^{\circ} \mathrm{C}$ at the same rate under a nitrogen atmosphere.

\subsubsection{Thermogravimetric Analysis}

Thermogravimetric analyses were carried out with PE Instruments equipment (STA 6000-SQ8, Waltham, MA, USA ). Samples with the weight of $10 \pm 0.5 \mathrm{mg}$ were heated from 50 to $600{ }^{\circ} \mathrm{C}$ at a constant rate of $10{ }^{\circ} \mathrm{C} / \mathrm{min}$ under a nitrogen atmosphere.

\subsubsection{Mechanical Testing}

Flexural and tensile tests were performed using an electromechanical universal testing machine (CMT5504, MTS, Shenzhen, China). According to ASTM D790 (Standard Test Methods for Flexural Properties of Unreinforced and Reinforced Plastics and Electrical Insulating Materials), the samples with dimension of $50 \times 12.7 \times 1.5 \mathrm{~mm}$ were prepared for the flexural tests. The test was carried out at a speed of $2 \mathrm{~mm} / \mathrm{min}$ with a support span of $25.4 \mathrm{~mm}$. According to ASTM D 638 (Standard Test Method for Tensile Properties of Plastics), dumbbell-shaped samples with the dimension of $115 \mathrm{~mm}$ in length, $19 \mathrm{~mm}$ in overall width, $6 \mathrm{~mm}$ in narrow width, and $1.5 \mathrm{~mm}$ in thickness were used for tensile tests, and the crosshead speed was set to $5 \mathrm{~mm} / \mathrm{min}$. Charpy impact tests of unnotched specimens were carried out with an impact machine (XJ-50G, Chengde, China) according to the Chinese standard (GB/T 1043). The dimension was $80 \times 10 \times 3 \mathrm{~mm}$. All the specimens were performed in the condition of $23 \pm 2{ }^{\circ} \mathrm{C}$ and $50 \pm 5 \%$ (Relative Humidity). At least five specimens were tested for each formulation.

\subsubsection{Morphological Analysis}

Cryo-fractured surfaces were generated by breaking the composites under liquid nitrogen conditions and subsequently sputter-coated with gold. The fractured surfaces were observed with a scanning electron microscope (QUNGTA200, FEI, Oregon, USA) at an accelerating voltage of $10 \mathrm{kV}$. 


\subsubsection{Dynamic Mechanical Analysis}

Dynamic mechanical analyses (DMA) of all samples were tested in three-point bending mode with Dynamic Mechanical Analyzer (Q800, TA, New Castle, USA). Rectangular specimens with a dimension of $35 \times 12 \times 1.5 \mathrm{~mm}$ were used. Experiments were carried out in the temperature range from -20 to $120^{\circ} \mathrm{C}$ with a heating rate of $5^{\circ} \mathrm{C} / \mathrm{min}$ and a constant frequency of $1 \mathrm{~Hz}$.

\section{Results and Discussion}

\subsection{Differential Scanning Calorimetry Analysis}

As the contents of $\mathrm{LiCl}$ increased, $T_{p}, T_{m}$, and $X_{c}$ of the composites declined (Figure 1 and Table 2). This was believed to be due to the break of hydrogen bonds between molecular chains by complexation of $\mathrm{LiCl}$ and amide groups [17]. The complexation restricted the motion of PA6 molecular chains, hence, the crystallization time showed the opposite trend (Table 2). $T_{p}, T_{m}$, and $X_{c}$ of the composites with $3 \mathrm{wt} \% \mathrm{LiCl}$ were disappeared (Figure 1 and Table 2), which demonstrated that the crystal morphology of PA6 was varied from semi-crystalline to amorphous state.
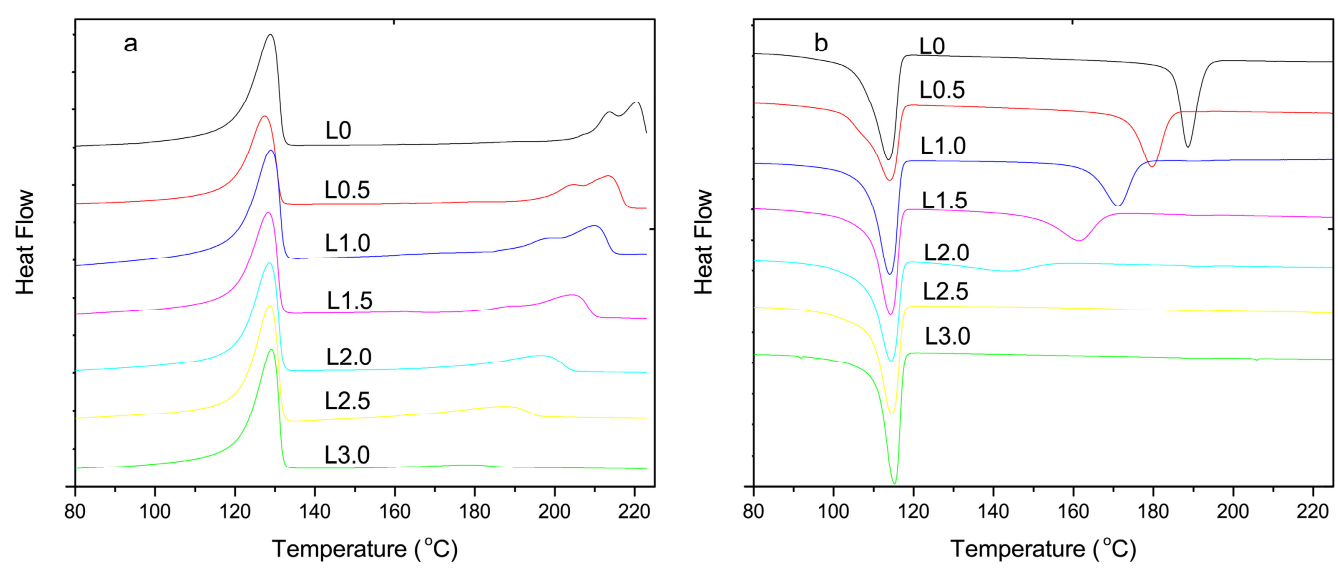

Figure 1. Differential Scanning Calorimetry (DSC) thermograms of composites with different $\mathrm{LiCl}$ contents: (a) melting curve; and (b) crystallization curve.

Table 2. DSC analysis data of composites with different $\mathrm{LiCl}$ contents.

\begin{tabular}{ccccc}
\hline Samples & $\boldsymbol{T}_{\boldsymbol{m}}\left({ }^{\circ} \mathbf{C}\right)$ & $\boldsymbol{T}_{\boldsymbol{p}}\left({ }^{\circ} \mathbf{C}\right)$ & Crystallization Time (s) & $\boldsymbol{X}_{\boldsymbol{c}}(\%)$ \\
\hline L0 & 220.4 & 188.6 & 47 & 20.0 \\
L0.5 & 213.4 & 179.7 & 64 & 19.2 \\
L1.0 & 209.9 & 171.1 & 78 & 17.8 \\
L1.5 & 204.5 & 161.3 & 107 & 15.3 \\
L2.0 & 197.0 & 143.3 & 169 & 10.9 \\
L2.5 & 187.5 & - & - & 9.4 \\
L3.0 & - & - & - & - \\
\hline$T_{m}:$ melting point of PA6; $T_{p}$ : peak temperature of crystallization of PA6; $X_{c}$ : crystallinity of PA6.
\end{tabular}

\subsection{Thermal Analysis}

The peak temperature $\left(T_{p}\right)$ of the thermal degradation of MCC, PA6, and HDPE was given in Table 3. As can be seen, the peak temperature of MCC decreased in the $\mathrm{LiCl}$ content range of $0-2.0 \%$, implying that $\mathrm{LiCl}$ could promote the degradation of MCC. Further increasing the $\mathrm{LiCl}$ content from $2.0 \%$ to $3.0 \%, T_{p}$ of MCC did not have a substantial change. This result may indicate that there existed a critical concentration of $\mathrm{LiCl}$. For PA6, the addition of $\mathrm{LiCl}$ significantly decreased the peak thermal degradation temperature, which is in agreement with the result that little $\mathrm{LiCl}$ could decrease the 
melting point of PA6. For HDPE, the incorporation of $\mathrm{LiCl}$ had a slight effect on the peak thermal degradation temperature.

Table 3. Degradation temperature values derived from thermogravimetric analysis.

\begin{tabular}{cccc}
\hline \multirow{2}{*}{ Samples } & \multicolumn{3}{c}{$\boldsymbol{T}_{\boldsymbol{p}}\left({ }^{\circ} \mathbf{C}\right)$} \\
\cline { 2 - 4 } & Peak A & Peak B & Peak C \\
\hline L0 & 366.2 & 442.5 & 482.7 \\
L0.5 & 350.8 & 429.9 & 483.7 \\
L1.0 & 343.0 & 422.9 & 480.8 \\
L1.5 & 336.2 & 420.6 & 480.6 \\
L2.0 & 319.8 & 418.5 & 479.8 \\
L2.5 & 317.1 & 423.2 & 482.5 \\
L3.0 & 314.6 & 421.0 & 483.1 \\
\hline
\end{tabular}

$T_{p}$ : the peak temperature of degradation; the temperature of Peak A, peak B, and peak $C$ are associated with the degradation of MCC, PA6, and HDPE, respectively.

\subsection{Mechanical Analysis}

The flexural strength of composites was slightly improved with increasing of $\mathrm{LiCl}$ content to $1.0 \%$ (Figure 2a). The increase may be attributed to the formation of pseudo-crosslinking structure by the complexation of $\mathrm{LiCl}$ and amide groups [17]. Further increasing the $\mathrm{LiCl}$ content from $1.0 \%$ to $2.0 \%$, the flexural strength of the composites decreased (Figure 2a). It may be due to the degradation of MCC promoted by $\mathrm{LiCl}$ (Table 3). However, the flexural strength of composites increased again when the $\mathrm{LiCl}$ content was above $2.0 \%$. The reason may be that the effect of the complexation which offset the degradation of MCC. It can be proved by that the increase of $\mathrm{LiCl}$ content (above $2.0 \%$ ) did not cause essential changes in the peak temperature of degradation (Table 3). $\mathrm{LiCl}$ prevented the motion of PA6 molecular chains and improved the stiffness of the composites, which can explain a slight increasing trend in the flexural modulus as the increase of $\mathrm{LiCl}$ content (Figure 2a).

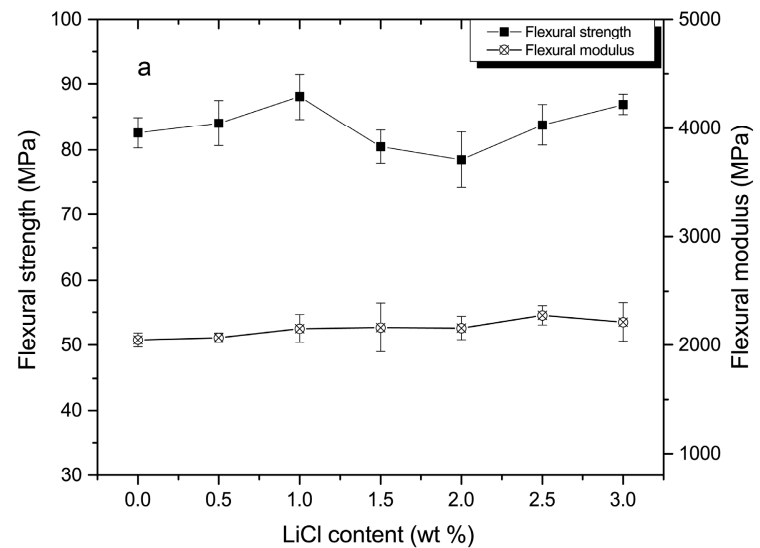

Figure 2. Flexural properties of composites: MAPE contents.

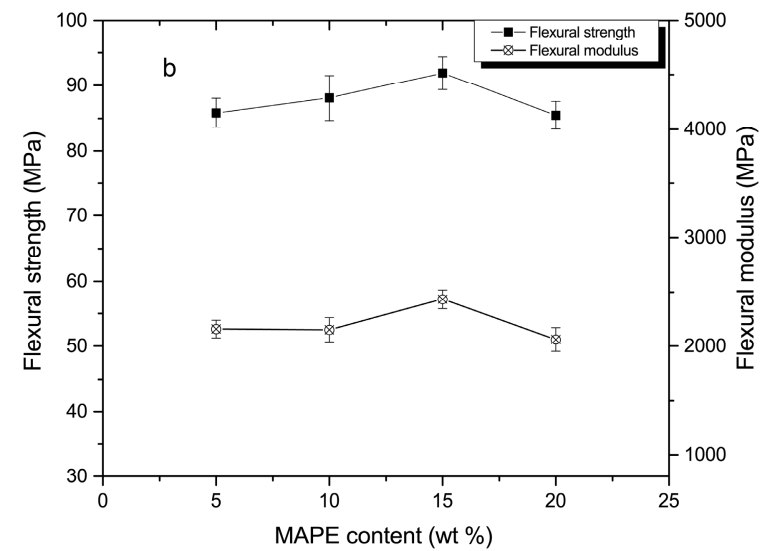

(a) in various $\mathrm{LiCl}$ contents; and (b) in various

The composites displayed an increase in flexural strength and modulus in the MAPE content range of 5-15\%, above which the flexural strength and modulus exhibited a decreasing trend (Figure $2 \mathrm{~b}$ ). As the compatibilizer, MAPE improved the interfacial adhesion and miscibility among PA6, HDPE, and MCC, where large amounts of the applied load may be transferred to the rigid PA6 and MCC. However, a multimolecular layer induced by excess MAPE (above 15\%) was formed on the surface of MCC and PA6. It is difficult to bear further external loads due to the multimolecular layer of MAPE [19]. Furthermore, as the polar polymer, excess MAPE (above 15\%) tended to aggregate and 
the formation of stress concentration decreased the flexural strength. The similar phenomenon that compatibilizers create a critical concentration have been observed in the literature [20]. The tensile strength of the composites exhibited the similar trend to the flexural strength, and the composites showed that the hardly-changed tensile modulus with the increase of LiCl and MAPE (Figure 3a,b). The composites revealed no obvious change in elongation at break with an increase of the $\mathrm{LiCl}$ content to $2.5 \%$. With a further increase of the $\mathrm{LiCl}$ content $(3.0 \%)$, the elongation at break of the composites was decreased significantly (Figure 3c).
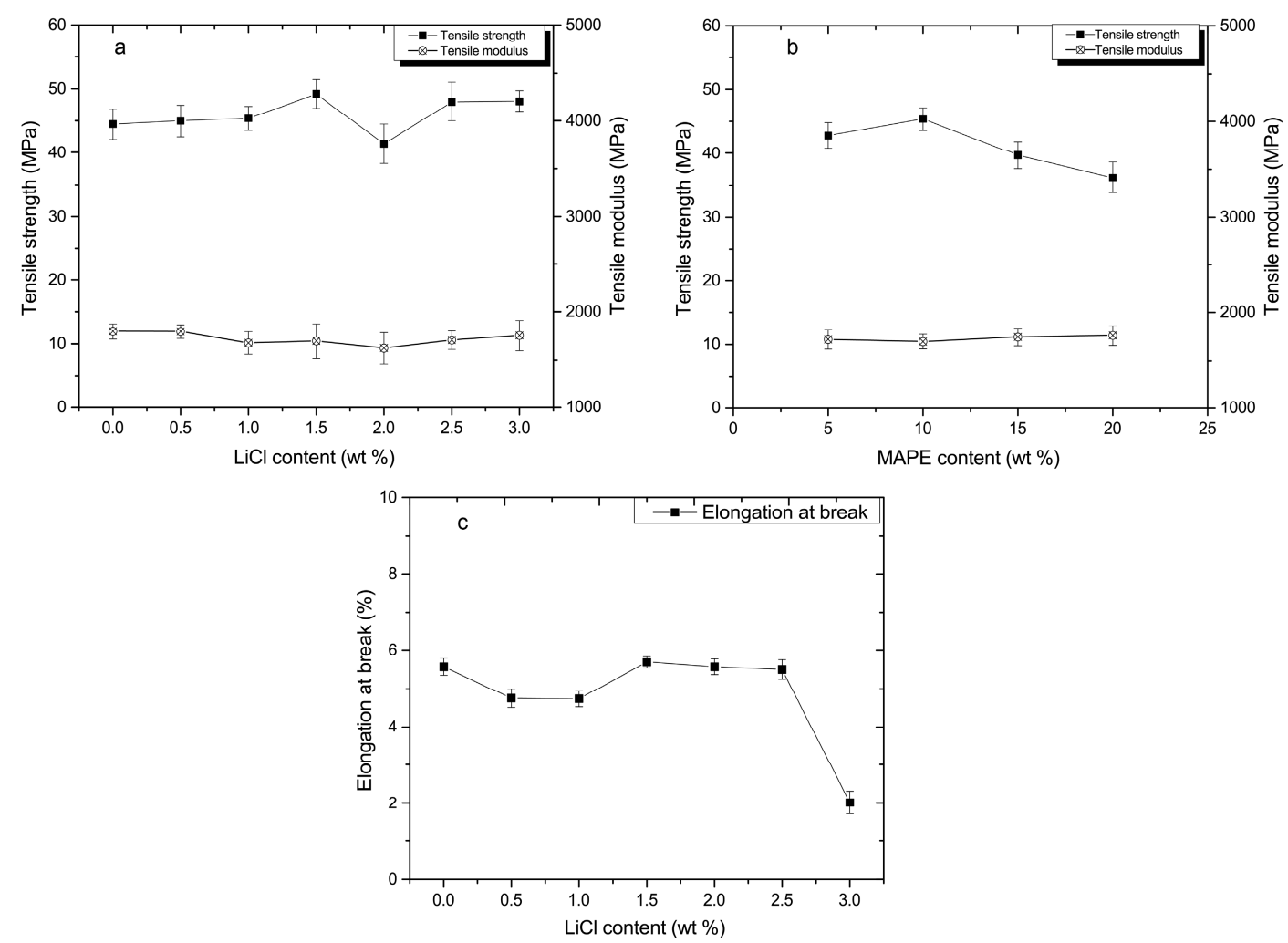

Figure 3. Tensile properties of composites: (a) tensile strength and modulus in various $\mathrm{LiCl}$ contents; (b) tensile strength and modulus in various MAPE contents; and (c) the elongation at break in various $\mathrm{LiCl}$ contents.

The impact strength of composites increased in the $\mathrm{LiCl}$ content range of $0-2.0 \%$, and then decreased with a further increase in the $\mathrm{LiCl}$ content (Figure $4 \mathrm{a}$ ). The composites gained an increase of $90 \%$ in the impact strength at a $\mathrm{LiCl}$ content of $2.0 \%$. In principle, rigid ionic bonding between PA6 chains with the addition of $\mathrm{LiCl}$ went against the stress dissipation, the external energy would be consumed during crack propagation by unstable crack growth mechanisms. As a result, the impact strength was decreased [15]. However, the increase of interfacial compatibility promoted by $\mathrm{LiCl}$ between PA6 and HDPE made the impact energy transferred and dissipated from rigid PA6 to flexible HDPE (as will be shown later by SEM analysis), which prevailed over the positive effect of rigid ionic bonding in the $\mathrm{LiCl}$ content range of $0-2.0 \%$. Increasing the $\mathrm{LiCl}$ content did not cause a substantial change of interfacial compatibility (above 2.0\%) (Figure 5). Hence, the effect of rigid bonding on energy dissipation may be dominant. This result may explain the decreasing impact strength (above $2.0 \%$ ). Compared to the composites with 5.0\% MAPE, the impact strength of the composites with 10.0\% MAPE was improved $10.6 \%$, and then gradually decreased with the increasing of MAPE (Figure 4b). An increase of the impact strength was ascribed to better interfacial adhesion between PA6 and HDPE (Figure 6), where the impact energy was dissipated via HDPE [6]. The decrease may be attributed to the following two reasons: (1) the weight ratio of HDPE decreased as the content of MAPE was 
increased, and there were no sufficient flexible polymers to absorb and dissipate the external energy; (2) the abovementioned formation of the multimolecular layer and stress concentration contributed to the decrease.
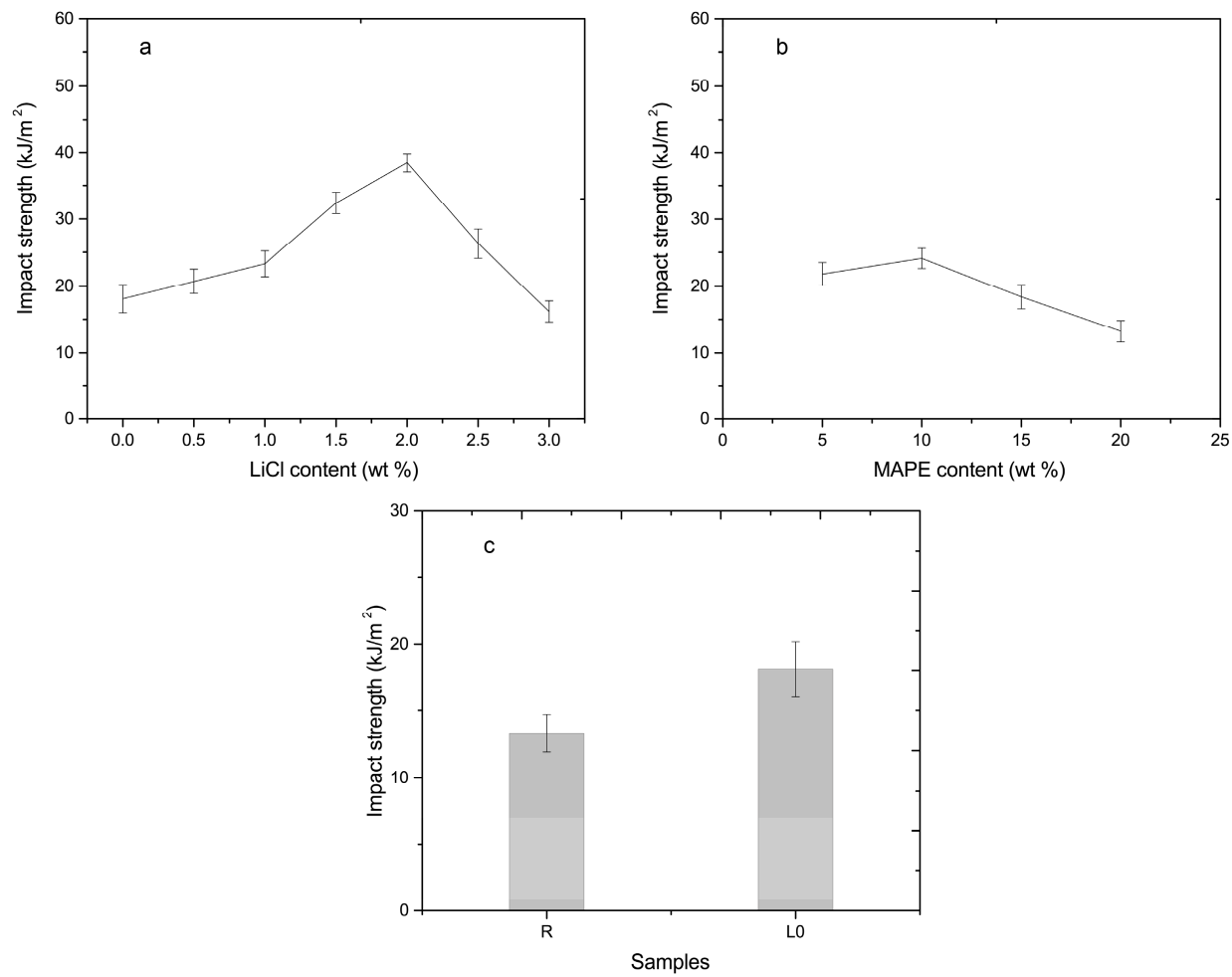

Figure 4. Impact properties of composites: (a) in various $\mathrm{LiCl}$ contents; (b) in various MAPE contents; and (c) PA6/MCC composites and PA6/HDPE/MCC composites without LiCl.
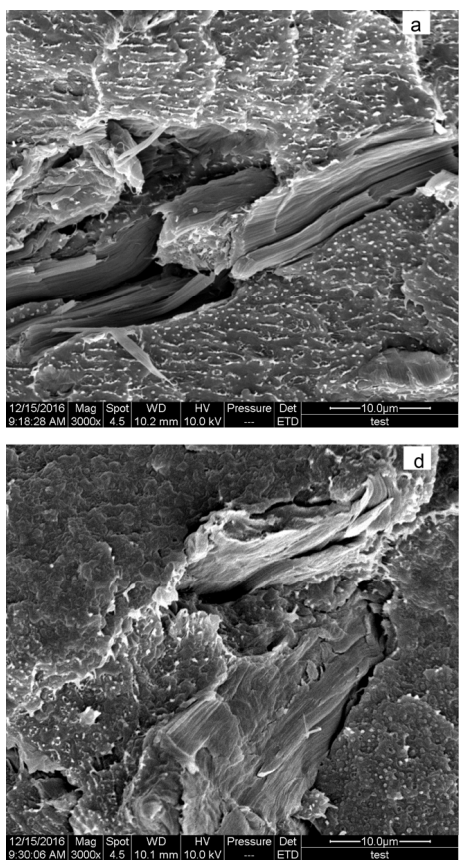
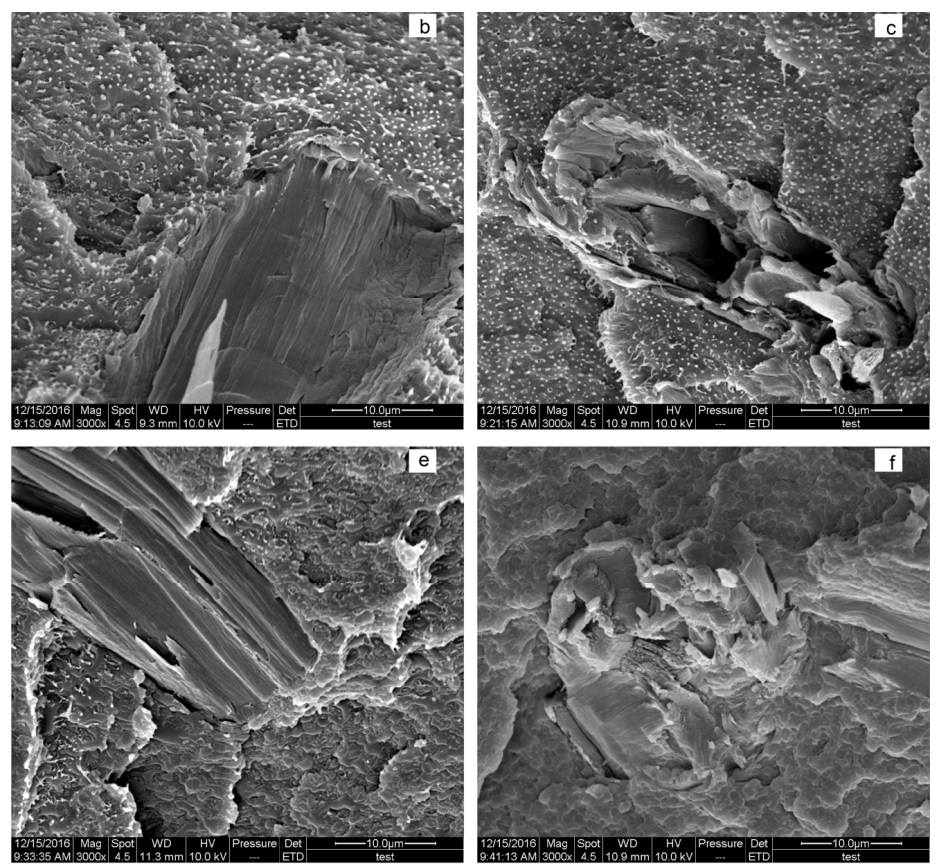

Figure 5. Cont. 

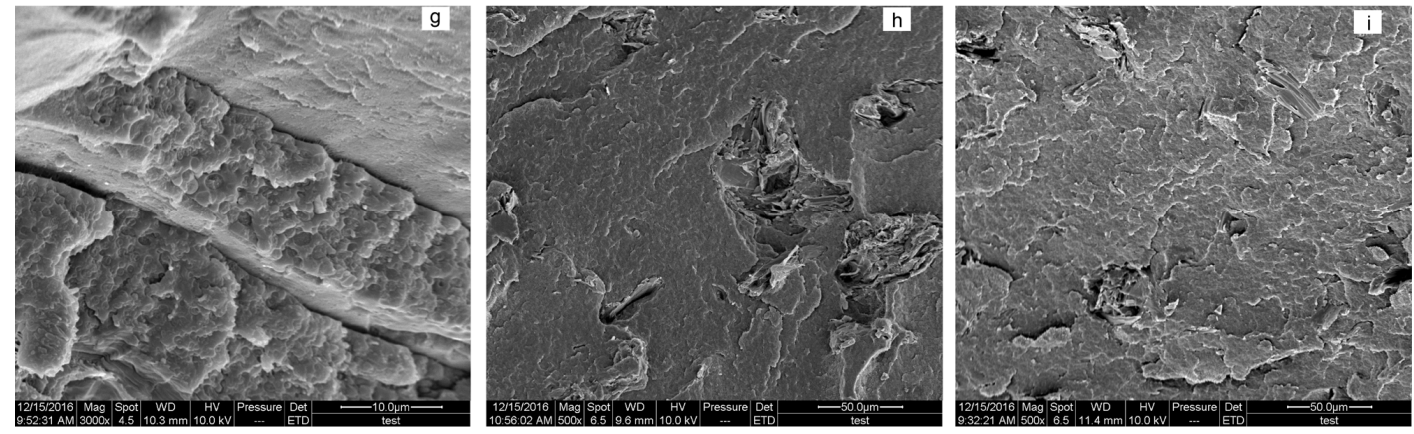

Figure 5. Morphologies of the composites in various $\mathrm{LiCl}$ contents and scale bar: (a) $0 \%(10 \mu \mathrm{m})$; (b) $0.5 \%(10 \mu \mathrm{m}) ;(\mathbf{c}) 1.0 \%(10 \mu \mathrm{m}) ;(\mathbf{d}) 1.5 \%(10 \mu \mathrm{m}) ;(\mathbf{e}) 2.0 \%(10 \mu \mathrm{m}) ;(\mathbf{f}) 2.5 \%(10 \mu \mathrm{m}) ;(\mathrm{g}) 3.0 \%(10 \mu \mathrm{m})$; (h) $0 \%(50 \mu \mathrm{m})$; and (i) $2.0 \%(50 \mu \mathrm{m})$.
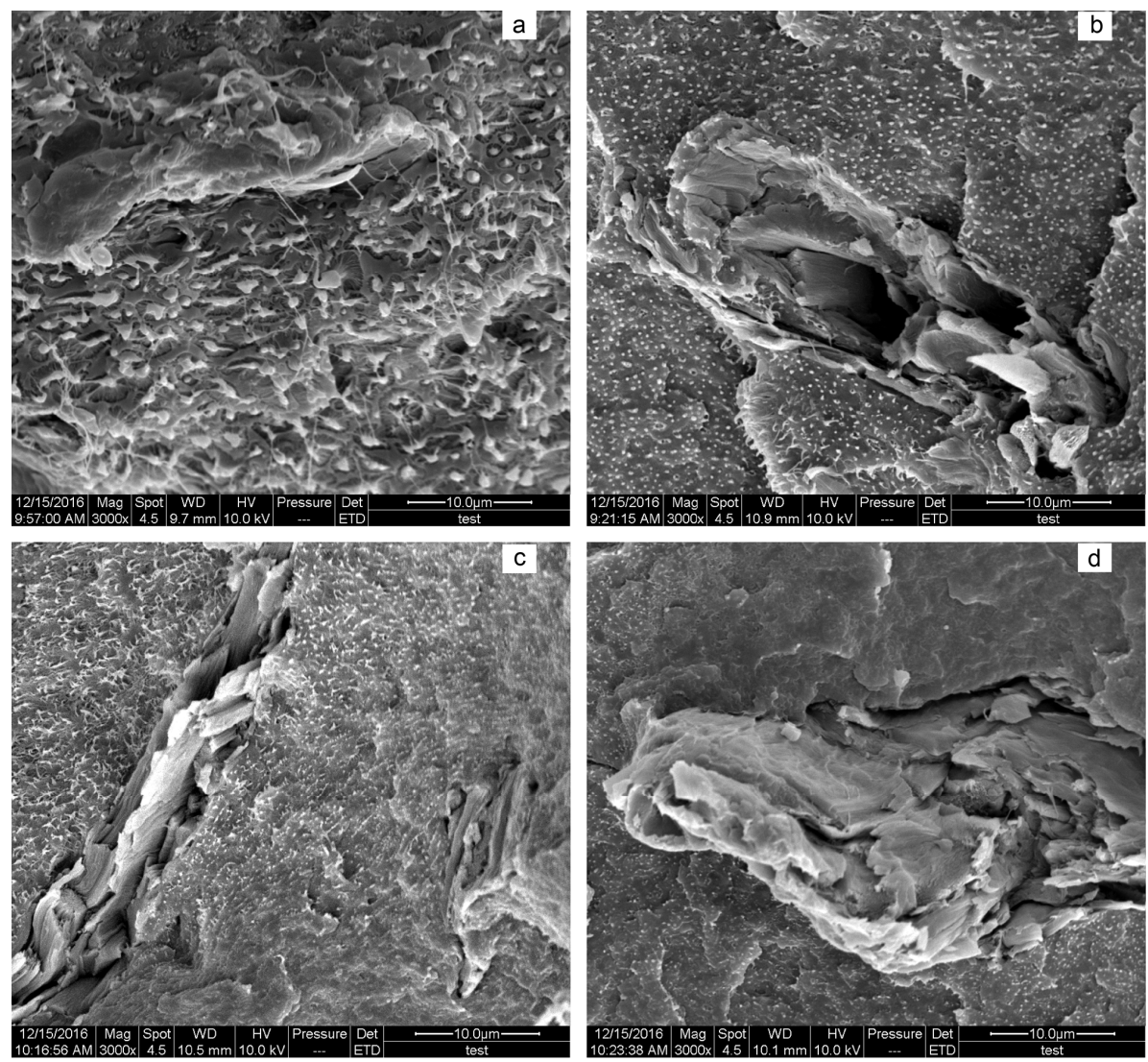

Figure 6. Morphologies of the composites in various MAPE contents: (a) 5\%; (b) 10\%; (c) 15\%; and (d) $20 \%$.

The impact strength of PA6/HDPE/MCC composites increased by $36 \%$ compared to PA6/MCC composites (Figure 4c), which was ascribed to energy dissipation of flexible HDPE [6].

\subsection{Morphology Analysis}

In the composites without $\mathrm{LiCl}$, large amounts of HDPE were dispersed in the continuous phase of PA6 in the form of stripe, strap, and other irregular shapes in the length range of 1 to $5 \mu \mathrm{m}$ (Figure 5a), implying that although MAPE was applied as the compatibilizer, there was still weak interfacial adhesion between PA6 and HDPE with a MAPE content of 10\%. The shapes of HDPE 
shifted toward much smaller globular particles in size in the PA6 matrix with a $\mathrm{LiCl}$ content range of $0.5-1.0 \%$ (Figure $5 b, c$ ). With the further increase of $\mathrm{LiCl}$, the globular particles were diminished, and then vanished (Figure $5 \mathrm{~d}-\mathrm{g}$ ). The above observation obviously disclosed that $\mathrm{LiCl}$ was in favor of interfacial adhesion between PA6 and HDPE, which may be explained by the following two reasons: (1) lithium cations of electron deficiency complexed with $\mathrm{O}$ or $\mathrm{N}$ of both amide groups and anhydride groups. As a result, more molecular chains of MAPE and PA6 were connected via $\mathrm{LiCl}$ (Figure 7); and (2) amorphous PA6 chains were increased with the increase of $\mathrm{LiCl}$, it was easier for anhydride groups with high steric hindrance to penetrate into the inside of amorphous PA6. Consequently, the interfacial compatibility was improved by more chemical reaction between end amino groups of PA6 and anhydride groups of MAPE [21].

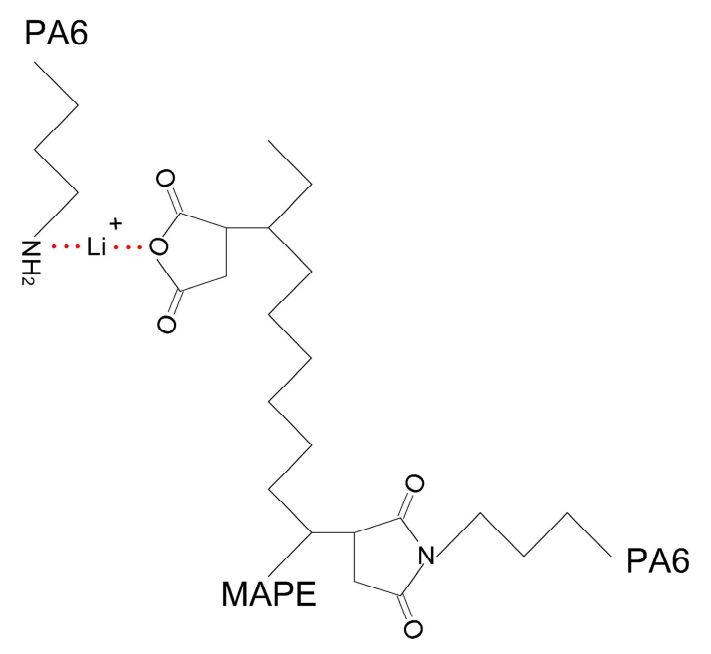

Figure 7. Scheme of complexation between $\mathrm{LiCl}$ and $\mathrm{O}$ or $\mathrm{N}$.

Figure 5h,i indicated that MCC was uniformly distributed in the composites, and MCC was broken rather than pulled out. A rougher surface and more cracks were observed in the composites with $2.0 \% \mathrm{LiCl}$ than the composites without $\mathrm{LiCl}$. This further proved that $\mathrm{LiCl}$ improved the impact strength via the energy dissipation mechanism [6].

In contrast with the composites at the MAPE content of 5\%, the particle size of HDPE was reduced by one to two orders of magnitude for the composites with 10\% MAPE, indicating that MAPE had the positive effect on compatibility between PA6 and HDPE. With the further increase in MAPE content, there was no significant change in the particle size of dispersive phase, except that the amounts of particles diminished slowly.

\subsection{Dynamic Mechanical Analysis}

The storage modulus of the composites without $\mathrm{LiCl}$ was lower than those with $\mathrm{LiCl}$ below the room temperature (Figure 8a), which can be explained by the complexation of $\mathrm{LiCl}$ and amide groups that restricted the molecular chains' motion of PA6. Above the glass transition temperature, the free volume of amorphous polymers will be expanded. Although it is impossible for the entire molecular chains to move, the thermal energy can overcome the barrier of internal rotation so that segmental movement of PA6 can be activated. As a result, the storage modulus was decreased. The more amorphous polymers, the lower the storage modulus, which can explain that the storage modulus of the composites was decreased with the increase of $\mathrm{LiCl}$ content above the glass transition temperature (Figure 8a). The storage modulus of the composites increased in the MAPE content range of 5-15\%, and then decreased with a further increase in the MAPE content (Figure 8c), which was in agreement with flexural modulus (Figure 2b). 

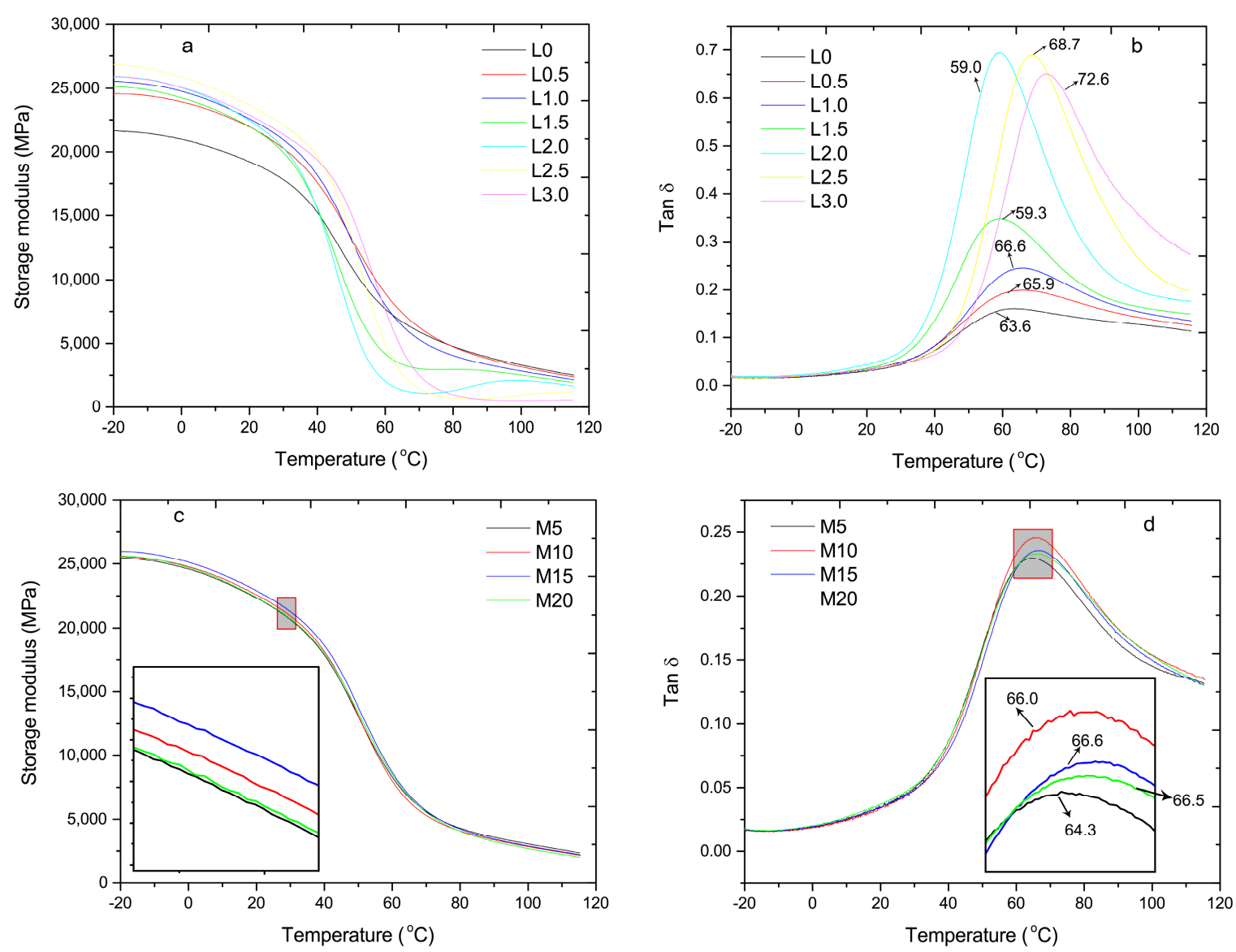

Figure 8. Dynamic mechanical properties for composites: (a) the storage modulus ( $\mathrm{E}^{\prime}$ ) in various $\mathrm{LiCl}$ contents; (b) the loss factor (Tan $\delta$ ) in various $\mathrm{LiCl}$ contents; (c) the storage modulus in various MAPE contents; and (d) the loss factor in various MAPE contents.

The incorporation of $\mathrm{LiCl}$ significantly affected the glass transition temperature of PA6. The glass transition temperature was improved by $3{ }^{\circ} \mathrm{C}$ in the $\mathrm{LiCl}$ content range of $0-1.0 \%$, then was decreased in the $\mathrm{LiCl}$ content range of $1.5-2.0 \%$. Further increase of the $\mathrm{LiCl}$ content (above $2.5 \%$ ) caused an increase in the glass transition temperature (maximum was $72.6{ }^{\circ} \mathrm{C}$ ) (Figure 8b). An increase could be attributed to the restriction of PA6 molecular chains motion via complexation of $\mathrm{LiCl}$ and amide groups. Furthermore, the hydrogen bonds between the hydroxy of MCC and amide groups of PA6 could be generated. Thereby, a sharp degradation of MCC had a negative effect on the glass transition temperature of PA6 (Table 3), which explained the decrease in the $\mathrm{LiCl}$ content range of 1.5-2.0\%.

The composites demonstrated an increase of the peak width in $\tan \delta$ with the increasing of $\mathrm{LiCl}$ (Figure $8 b$ ), which could be ascribed to the following reasons: (1) the miscibility and interfacial adhesion between PA6 and HDPE was improved via $\mathrm{LiCl}$ (Figure 5), which was usually observed in miscible polymer blends [22]; and (2) constraints of the molecular chains' motion of PA6 resulted in an increase in the segmental relaxation time of PA6 [23]. The value of $\tan \delta$ is related to the viscoelastic response of the materials. A higher $\tan \delta$ of the composites suggested that the viscous nature was more dominant than the elastic property, as evidenced by the greater impact strength $[24,25]$. Tan $\delta$ of the composites was increased in the $\mathrm{LiCl}$ content range of $0-2.0 \%$, and then was decreased with further increasing of the $\mathrm{LiCl}$ content (Figure 8b). This trend was consistent with the impact strength (Figure 4a). An increase in compatibility and interfacial adhesion between PA6 and HDPE confined the movement of PA6 chain, thereby, the glass transition temperature was increased (Figure 8d). In addition, $\tan \delta$ of the composites and the impact strength followed the same trend with the increasing of MAPE. 


\section{Conclusions}

The results indicate that the addition of $\mathrm{LiCl}$ and HDPE is a novel and effective approach to increase the impact strength of PA6/MCC composites, as evidenced by the fact that the impact strength of composites was increased by $90 \%$ and $36 \%$, respectively. Morphology analysis demonstrated both $\mathrm{LiCl}$ and MAPE have a positive effect on the interfacial adhesion of the composites. In addition, $\mathrm{LiCl}$ is in favor of the glass transition temperature of composites (the maximum is $72.6^{\circ} \mathrm{C}$ ).

Acknowledgments: This work was financially supported by the Fundamental Research Funds for the Central Universities (No. 2572016AB60, 2572015BX02) and Natural Science Foundation of Heilongiang Province of China (QC2016017).

Author Contributions: Shihua $\mathrm{Xu}$ and Jun He conceived and designed the study; Shihua $\mathrm{Xu}$ and Shunmin Yi performed the experiments; Shihua $\mathrm{Xu}$ and Yiqun Fang wrote the paper; and Shihua $\mathrm{Xu}$, Haigang Wang, and Qingwen Wang analyzed the data.

Conflicts of Interest: The authors declare no conflict of interest.

\section{References}

1. Kossentini-Kallel, T.; Houichi, H. Reactive blending of PE-GMA/PA6 effect of composition and processing conditions. Polym. Adv. Technol. 2015, 26, 539-545. [CrossRef]

2. Chow, W.S.; Ishak, Z.A.M. Polyamide blended-based nanocomposites: A review. Express Polym. Lett. 2015, 9, 211-232. [CrossRef]

3. Dasdemir, M.; Maze, B.; Anantharamaiah, N.; Pourdeyhimi, B. Reactive compatibilization of polyamide 6/polyethylene nonwoven based thermoplastic composites. Eur. Polym. J. 2015, 63, 194-206. [CrossRef]

4. Attari, M.; Arefazar, A.; Bakhshandeh, G. Mechanical and thermal properties of toughened PA6/HDPE/SEBS-g-MA/Clay nanocomposite. Polym. Eng. Sci. 2015, 55, 29-33. [CrossRef]

5. Wang, W.; Dou, R.; Zhou, Y.; Li, L.P.; Yin, B.; Yang, M.B. The influence of mixing order on the phase inversion and crystallization behavior of polyamide 6/maleic anhydride-g-ethylene-propylene-diene rubber/high-density polyethylene blend. J. Elastom. Plast. 2015, 47, 608-624. [CrossRef]

6. Apollonio, C.; Covas, D.I.C.; de Marinis, G.; Leopardi, A.; Ramos, H.M. Creep functions for transients in HDPE pipes. Urban Water J. 2014, 11, 160-166. [CrossRef]

7. Covas, D.; Stoianov, I.; Mano, J.F.; Ramos, H.; Graham, N.; Maksimovic, C. The dynamic effect of pipe-wall viscoelasticity in hydraulic transients. Part I-Experimental analysis and creep characterization. J. Hydraul. Res. 2004, 42, 516-530. [CrossRef]

8. Covas, D.; Stoianov, I.; Mano, J.F.; Ramos, H.; Graham, N.; Maksimovic, C. The dynamic effect of pipe-wall viscoelasticity in hydraulic transients. Part II-Model development, calibration and verification. J. Hydraul. Res. 2005, 43, 56-70. [CrossRef]

9. Pappu, A.; Patil, V.; Jain, S.; Mahindrakar, A.; Haque, R.; Thakur, V.K. Advances in industrial prospective of cellulosic macromolecules enriched banana biofibre resources: A review. Int. J. Biol. Macromol. 2015, 79, 449-458. [CrossRef] [PubMed]

10. Thakur, V.K.; Thakur, M.K.; Gupta, R.K. Rapid synthesis of graft copolymers from natural cellulose fibers. Carbohydr. Polym. 2013, 98, 820-828. [CrossRef] [PubMed]

11. Trache, D.; Hussin, M.H.; Chuin, C.T.H.; Sabar, S.; Fazita, M.R.N.; Taiwo, O.F.A.; Hassan, T.M.; Haafiz, M.K.M. Microcrystalline cellulose: Isolation, characterization and bio-composites application-A review. Int. J. Biol. Macromol. 2016, 93, 789-804. [CrossRef] [PubMed]

12. Bai, W.; Li, K.C. Partial replacement of silica with microcrystalline cellulose in rubber composites. Compos. Part A-Appl. Sci. Manuf. 2009, 40, 1597-1605. [CrossRef]

13. Lamnawar, K.; Baudouin, A.; Maazouz, A. Interdiffusion/reaction at the polymer/polymer interface in multilayer systems probed by linearviscoelasticity coupled to FTIR and NMR measurements. Eur. Polym. J. 2010, 46, 1604-1622. [CrossRef]

14. Yordanov, C.; Minkova, L. Fractionated crystallization of compatibilized LDPE/PA6 blends. Eur. Polym. J. 2005, 41, 527-534. [CrossRef]

15. Argoud, A.; Trouillet-Fonti, L.; Ceccia, S.; Sotta, P. Morphologies in polyamide 6/high-density polyethylene blends with high amounts of reactive compatibilizer. Eur. Polym. J. 2014, 50, 177-189. [CrossRef] 
16. Amintowlieh, Y.; Sardashti, A.; Simon, L.C. Polyamide 6-wheat straw composites: Degradation kinetics. Polym. Compos. 2012, 33, 985-989. [CrossRef]

17. Amintowlieh, Y.; Sardashti, A.; Simon, L.C. Polyamide 6-wheat straw composites: Effects of additives on physical and mechanical properties of the composite. Polym. Compos. 2012, 33, 976-984. [CrossRef]

18. Amintowlieh, Y. Nylon-6/Agricultural Filler Composites. Ph.D. Dissertation, University of Waterloo, Waterloo, ON, Canada, 2010.

19. Cai, H.Z.; Yi, W.M.; Bai, X.Y. Effect of coupling agents on the mechanical properties of wheat straw flour \& polyethylene composites. In Proceedings of the 2011 International Conference on Manufacturing Science and Technology, Singapore, 16-18 September 2011.

20. Liu, H.; Wu, Q.; Han, G.; Yao, F.; Kojima, Y.; Suzuki, S. Compatibilizing and toughening bamboo flour-filled HDPE composites: Mechanical properties and morphology. Compos. Part A Appl. Sci. Manuf. 2008, 39, 1891-1900. [CrossRef]

21. Shao, H.J.; Wu, B.; Yang, J.K.; Zhang, K.Z.; Qin, S.H. Effect of LiCl on the miscibility and crystallization behavior of a hydrophilic PP/PP-g-MAH/PA6 blend. J. Polym. Res. 2015, 22. [CrossRef]

22. Sallem-Idrissi, N.; Sclavons, M.; Debecker, D.P.; Devaux, J. Miscible raw lignin/nylon 6 blends: Thermal and mechanical performances. J. Appl. Polym. Sci. 2016, 133. [CrossRef]

23. Verghese, K.N.E.; Jensen, R.E.; Lesko, J.J.; Ward, T.C. Effects of molecular relaxation behavior on sized carbon fiber-vinyl ester matrix composite properties. Polymer 2001, 42, 1633-1645. [CrossRef]

24. Taividi, M.; Falk, R.H.; Hermanson, J.C. Effect of natural fibers on thermal and mechanical properties of natural fiber polypropylene composites studied by dynamic mechanical analysis. J. Appl. Polym. Sci. 2006, 101, 4341-4349. [CrossRef]

25. Liu, T.; Wang, Q.W.; Xie, Y.J.; Lee, S.; Wu, Q.L. Effects of use of coupling agents on the properties of microfibrillar composite based on high-density polyethylene and polyamide-6. Polym. Bull. 2014, 71, 685-703. [CrossRef]

(C) 2017 by the authors. Licensee MDPI, Basel, Switzerland. This article is an open access article distributed under the terms and conditions of the Creative Commons Attribution (CC BY) license (http:/ / creativecommons.org/licenses/by/4.0/). 